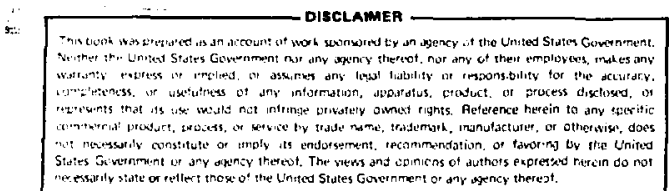

LARGE ASPECT Ratio tokAMAK STUU* CONF- $991102-156$

R. L. Reid, J. A. Holmes, W. A. Houlberg, Y-K.M. Peng, and D. J. Strickler

Oak Rijge National Laboratory

Oak Ridge, Tennessee 37830

MASTER

T. G. Brown, C. Sardella, and G. H. Wiseman

Grumman Aerospace Corporation

Beshpage, New York 11714

Summary

The Large Aspect Ratio Tokamak Study (LARTS) investigated the potential for producing a viable long burn cokamak reactor through enhanced volt-second capability of the ohmic heating transformer by employing high aspect ratio designs. The plasma physics, engineering; and economic implications of high aspect ratio tokamaks were accessed in the context of extended burn operation. Plasma startup and burn parameters were addressed using a one-dimensional transport code. The pulsed electrical power requirements for the poloidal field system, which have a major impact on reactor economics, were minimized by optimizing the field in the ohmic heating coil and the wave shape of the ohmic heating discharge. A high aspect ratio reference reactor was chosen and configured.

\title{
Introduction
}

A tokamak with a long burn pulse is desirable in order to ameliorate the effect of the pulsed operation of the tokamak on the cyclic fatigue problem for the blanket first wall. Current reactor design studies generally assume $10^{4}-10^{5}$ pulses/yr. Concern has been expressed that such pulse rates could linit the lifetime of a stainless steel first wall to about 1-2 years. If the burn time could be extended by an order of magnitude relative to current assumptions, first wall lifetimes of at least 10 years would be projected.

Preliminary results from this study indicate that the desired order of magnitude increase in tokamak burn time can be achieved by using large aspect ratio designs with reasonable increases in capital cost. Values of cost, burn time, power output, plasma current, etc. were generated by an updated ORVL System Code, ORNL/TM-5813, and are referenced to the ORNL FY78 TNS Reference Reactor Design. I The high aspect ratio devices are expected to yield a lower value of beta than moderate aspect ratio devices. For this study, the beta limit was assumed to vary inversely with aspect ratio. A represertative large aspect ratio design, an aspect ratio of 8, producing $1000 \mathrm{MWe}$, appears to be an attractive compromise between increased burn tine (of the order of hours) and increased cost.

\section{Parametric Analysis}

Tokamak performance parameters as a function of aspect ratio at a reactor power level of 1000 MWe are shown in Fig. 1. These performance parameters, i.e., burn time, flasma size, nagnetic field, thermal power, and capital cost were obtained with the ORNL System Code, supplemented with detailed calcuiations for the poloidal field ccil and power supply systems, and are referenced to an updated CRNL FY78 TNS Reference Reactor Design. The parameters are consistent with a fixed neutron wall loading of $3.0 \mathrm{~mW} / \mathrm{m}^{2}$ at the plasma edge. The values of beta associated with these

Tesearch sponsored by the Cffice of Fusion Energy, U.S. [epartment of Energy under contract W-7405-eng-25 with the Union Caroide Corporation.

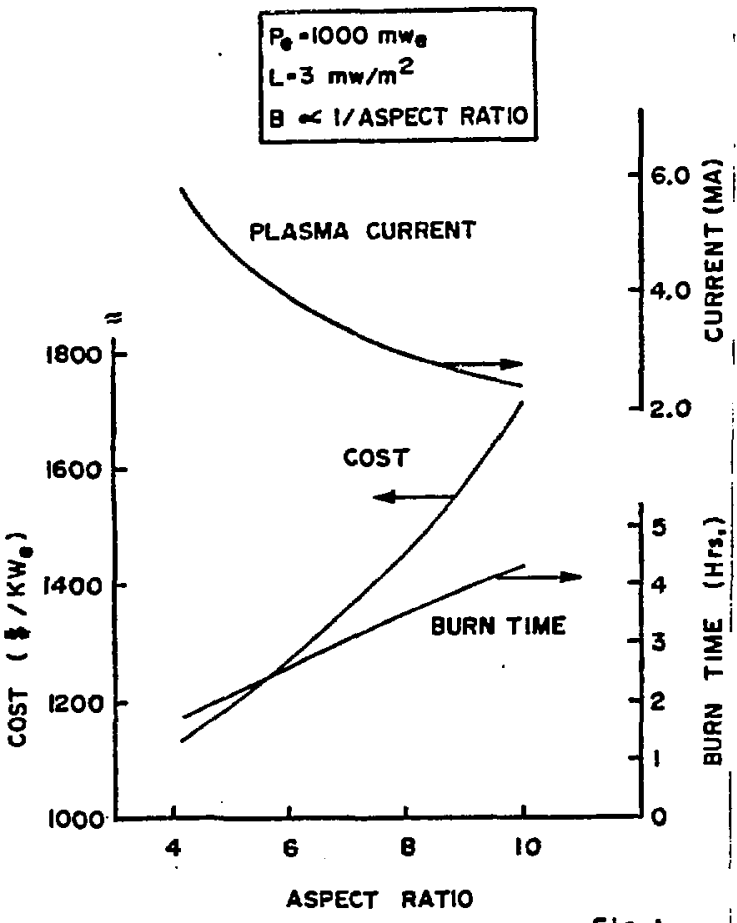

Fig. I

parameters were taken to vary inversely with aspect ratio. Burn time was assumed to be limited by voltseconds consideration only. Shield space, ripple, plasma clongation, safety factor, plisma temperature, $Z$ eff, and $P F$ coil configuration were taken to be the same as in the TWS design. The field in the ohmic heating solenoid was swing from plus 8.0 to minus 8.0 tesla during stare up and burn. Figure 1 snows the trade between unit capital cost, burn time, and plasma current as a function of aspect ratio at a constant neutron wall loading of $3 \mathrm{~mm} / \mathrm{m}^{2}$ and for a selected reactor power level of $100 \mathrm{C}$ WWe. Based on this figure, a tokanak with an aspect ratio of 8 was chosen as the representative LARTS reference point for morc detailed plasma physics and configurational analysis. This design represents a reasonable compromise between increased burn time and increased cost as aspect ratio is increased at a constant power level. The selected configuration achieves a burn time of 3.5 hours which recluess the number of burn cycles at least an order of magnitude roiative to a TiS type reactor at an increase of approximately 30 percent in unit capital cost.

Alpha containment was an initial concern when considering iarge aspect ratio designs since plasma current decreases with increasing aspect ratio as indicated in Figure 1. However, alpia containment scales linearly with the product of plasma current and aspet ratio, therefore, the large aspect ratio designs 
of Figure $!$ are sufficient in containing $3.5 \mathrm{MeV}$ alphas.

\section{Point Design}

Parameters for the represencative LART configuration (aspect ratio of $8.0,1000$ swe) are presented in table 1 , and plan and elevation views of this reactor are shown in Figures 2 and 3.

Table 1. LARTS Representative Configuration

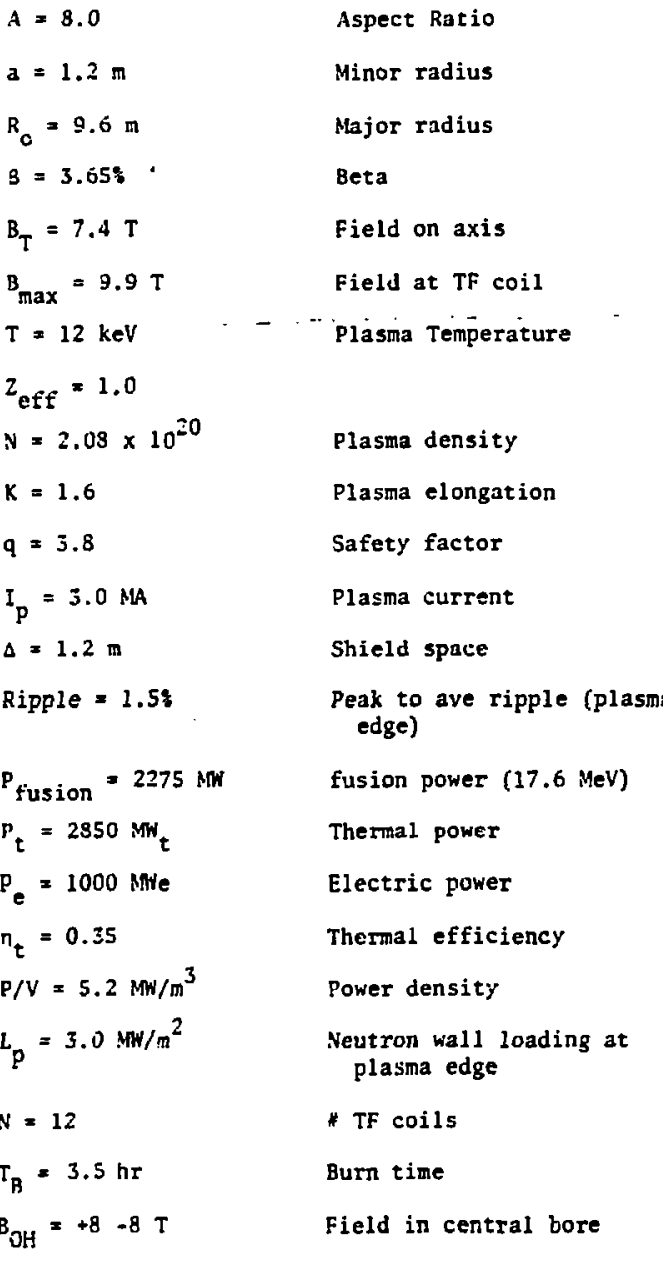

A numbar of changes were made in the configuration of the CARTS design compared to the earlier ORNL TNS configuration. The mast striking difference is the dewar system of LARTS which encompass all the superconducting soils, TF, exterior EF coils, and the $\mathrm{OH}$ solenoid as opposed to the separate dewars of the TF and exterior EF coils of the TNS desigr. The TF/EF dewar system in the LARTS design separates the warm and cold components and simplifies their structural support and thermal isolation. Exterior EF coils are supporzed off the intercoil structure with a linkage system that transmits dead weight and intercoil forces between the upper and lower exterior EF coils to the TF intercoil structure.

The total weight of the exterior EF coils, TF coils, and ofl solenoid is supported by the bucling cylinder which is bolted to the machine support base. The bucking cylinder is made from twelve segments which are insulated at each interface and bolted together. A nitrogen interface separates the bucking cylinder and the machine support base, with the length and truss construction of the machine support base designed to minimize the thermal heat load.

The large toroidal bore of the LARTS device, resulting from the high aspect ratio, allows space for a cylindrical dewar to be placed inside the oll solenoid as opposed to extending the dewar across the bore. This reduces the dewar support structure span length and thereby its structural requirenents.

The RF system was located on ground level instead of at the top of the device, as in the earlier InS design, to reduce the distince to the RF power supplies which are assumed to be located at a basement level.

The large aspect ratio results in twelve relatively wide $T F$ coils, assuning the coils bitt at the inner $\mathrm{leg}$, as shown in the plan and elevation views. These wide coils compromise accessibility for torus segment removal. The torus for LARTS must be divided into 24 segments to allow removal between TF coils as opposed to 16 torus segments in the TNS design. If the constraint of butting the TF coils at the inner leg were removed, the coils could be separated by spacers and reduced in width, accompanied by a proportional increase in depth, to enhance ascessibility. However, the ohmic heating coil bore would be decreased (less burn time) and ripple at the inside leg of the TF coil would be increased. This option needs additional study to verify reasibility.

\section{Plasma Physics Considerations}

Startup and burn parameters for the representative LART configuration were determined. A 50-50 mixture of deuteriun and tritium was maintained by control of the gas pufting rate. The beta limit was taken to vary inversely with aspect ratio as theoretically predicted. $A$ four-seccnd heating phase followed by an excursion to a steady state burn regime was the startup scenario used in this analysis.

\section{Transport Model}

A one-dimensional transport code, HHIST, ${ }^{2}$ was used in this analysis. Particle and energy transport in the plasma are modeled with a combination of neoclassical transport, ripple-enhanced ion thermal conduction, and anomalous particle diffusion and electron thermal conduction:

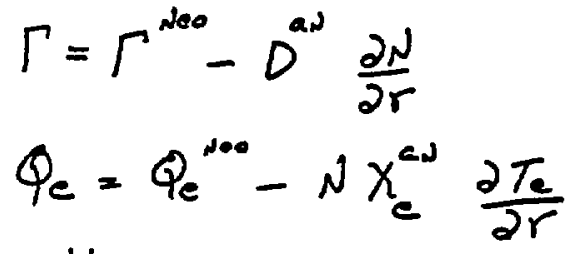

and
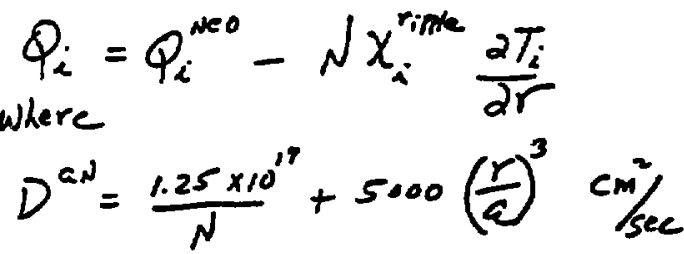

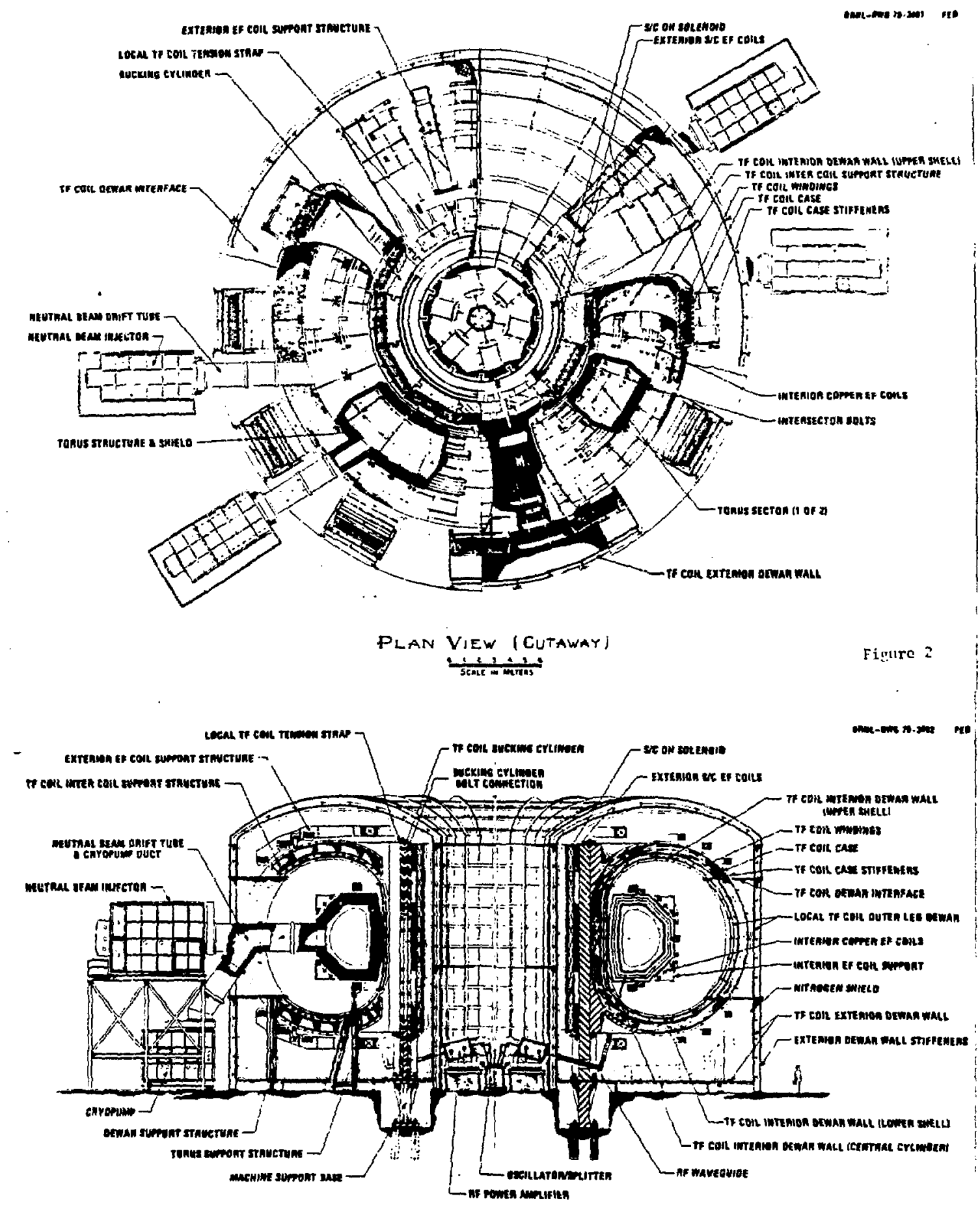

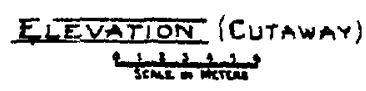

Figure 3 


\section{and}

$$
x_{e}^{a N}=\frac{1.0 \times 10^{17}}{N\left[1-.4\left(\frac{r}{c}\right)^{2}\right]^{3.5}} \frac{c m^{2}}{\sec }
$$

The transport coefficients for the anomalous terms are based on empirical fits to PLT data. ${ }^{3}$ The ripple enhanced ion conduction losses are calculated with the computer routine developed by Uckan, Uckan, and Moore. ${ }^{4}$ Ripple Effects

Toroidal field ripple is more uniform across the plasma as the aspect ratio is increased. For the same value of ripple at the plasma edge, a higher value of ripple exists at the plasma center for the large aspect ratio design. Therefore, it becomes important to reduce the maximum ripple in a large aspect ratio device relative to that in a lower aspect ratio device. There are three main classes of particles to consider when iscussing the effects of toroidal field ripple: particles locally trapped in the toroidal field ripple, particles that are trapped in the main toroical field (bananas), and circulating particles. We include only the first class of particles in the calculations presented in this study. This class includes a relatively small number of particles so the resulting particle loss rate is small. However, the particles which are lost are relatively energetic (collisionless) and the main effect can be modeled as enhanced ion thermal conduction.

The poloidal as well as radial variation in the ripple has a significant impact on the ion conduction loss. 5 For ease of flux surface averaging, it is advantageous to express the poloidal and radial variation of the ripple in separable form:

$$
\delta(r, \theta)=g(\theta) f(r)
$$

Based on a detailed computation of the magnetic field ripple for the l.ART design with 12 toroidal field coils, empirical fits to the radial and poloidal variation have been made. Figure 4 cepicts the radial variation in tile plasma midplane $(\theta=0)$ and Figure 5 shows the poloidal variation for several radii. The general fort for the fitting is diven by:

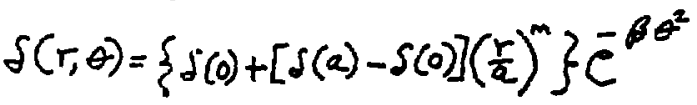

Because of the large aspect ratio and the twelve wide magnets used in the representative LART design, the ripple on the inside of the plasmi is large. The maximum in the roroidal field on the inside of the plasma occurs between magnets ratler than in the plane of the magnets. This is because the wide magnets are significantly closer to the plasina at this point. The traditiona: picture of ripple no ionger holds and the cirve fitting procedure used to describe the poloidal variation in ripple of figure 5 can be considered only marginally accurate.

There are several other adverse effects of toroidal field ripple which we have not inciuded in tinis analysis. As the plasma is heated, the flux
ORNL-DWG $79-3372$ FEO

\section{RIPPLE CONTOUR FIT FOR LART RADIAL VARIATION}

$\delta(0.0)=0.284$

$\delta(0,0)=! .125$

$\delta=\frac{\theta_{1}-\theta_{2}}{\theta_{1}+\theta_{2}}$

$B_{1}$-TOROIDAL FIELD in PLANE OF COIL

$B_{2}$-TOROIDAL FIELO BETWEEN COILS

$\delta(r, 0)=\delta(0)+[\delta(a)-\delta(0)]\left(\frac{f}{a}\right)^{m}$

$\theta=120 \mathrm{~cm}$

$R_{0}=960 \mathrm{~cm}$

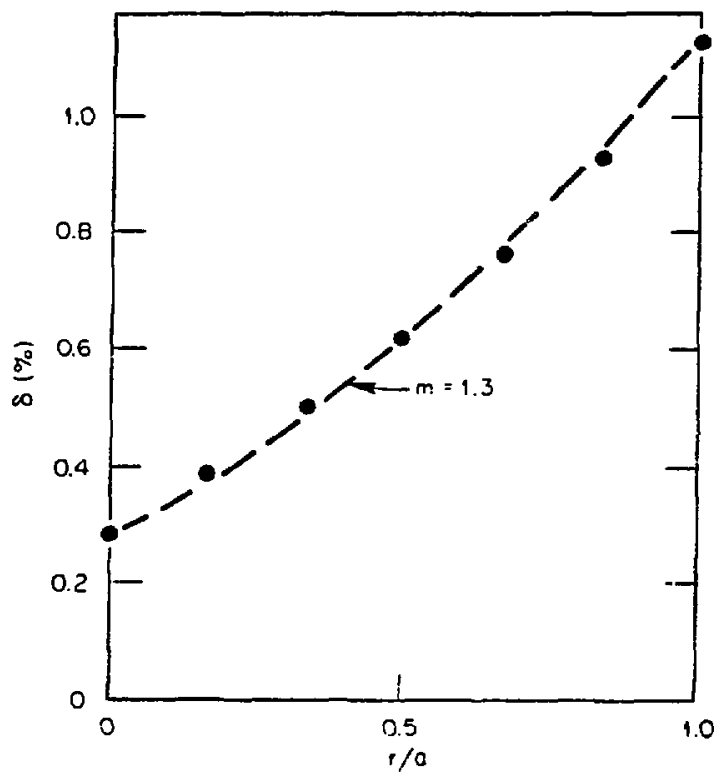

Figure 4

surfaces shift outward toward higher magnetic field ripple. This would increase the effectuve rifp:e. Since fast ions are preferestially depleted by the ripple, the tail of the ion distribution function will be decreased and the fusion rate will consequently decrease. The fusion rate for this study is based on an assumed Maxmellian ion distribution. The East alpha particles will also be affected by ripple. callen et al. ${ }^{6}$ have pointed out that fast alpha particles can scatter into the toroidal field ripple and drift out of the plasma. This reduces the amount of energy given to the background thermal ions.

\section{Startup and Burn}

A series of one-dimensional transport simulations were made using two start up-burn scenarios. The steady state burn parameters at the beta limit for each scenario is presented in Table 2. Paramezers associated with the second scenario are consistent with the parameters used in the parametric analysis section of this paper.

Scenario 1. Neutral beam heating was applied for four seconds. The neutral beam fower was varied to determine the minimum requirements for ignition 


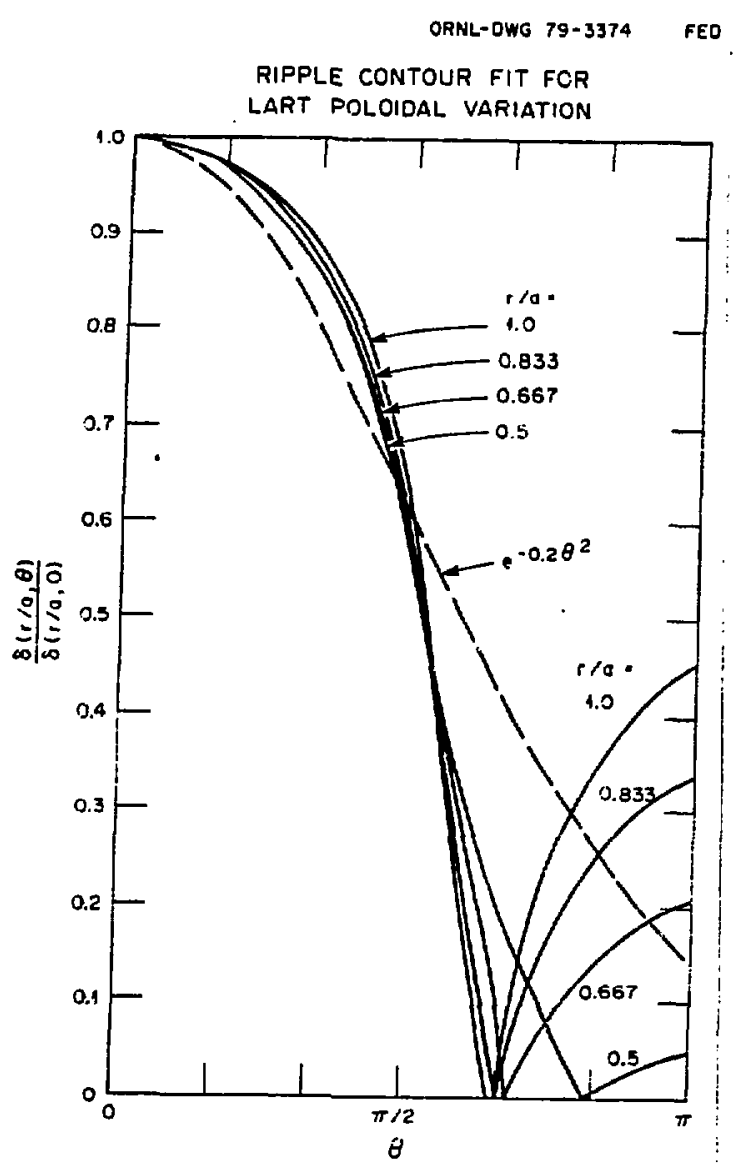

and after ignition was achieved, the steady state burn parameters were leternined as a function of $F$ lasma density. It was found that the ripple losses in LART were large enough to prevent ignition at values of beta deemed acceptable, plasma density $\leqslant 10^{1 \mathrm{~F}} \mathrm{~cm}^{-3}$

and beam power $100 \mathrm{NW}$. A 25\% reduction was made in the ripple (from 1.12 percent to 0.85 percent at the plasma edge) so that suitable burn regines could be found. The reduction in ripple for LART would, in practice, require modifications to the toroidal magnetic field design; even further reduction may be required if other ripple phenomena frove to be significart. Figure 6 shows plots of fusion pater, volume average beta, and average electron and ion temperature as a function of plasma density for steady state burn.

Parameters at the limiting value of beta, approximately 3.5 percent for an aspect ratio of 8 are taken fron this figure and presented in Table 2.

Scenario 2. Four seconds of neutral beam heating is applied to a low density plasma, $1 \times 10^{14} / \mathrm{cm}^{3}$. After ignition, density is increased to $2 \times 10^{14}$, at the beta limit of $3.5 \%$, while ripfle losses are increased to maintain a thermally stable olasma average temperature of approximazely $12 \mathrm{keV}$. This scenario allows higher density, lower tenperature plasmas, for the sane beta limit, then does Scenaris 1 . The parameters for this scenario are also shown in Table 2 and are basically consistent with the Reference LARTS parameters presented in Table 1. These same steady state reference parameters could be achieved witnout variable ripple by utilizing additional neutral beam power in conjunction with a low density start up.

Figure 5

Table 2. Startug/Steady State Plasma Parameters

\begin{tabular}{lcc}
\hline & Scenario 1 & Scenario 2 \\
\hline Beam injection, sec & 4 & 4 \\
Startup density, $\mathrm{cm}^{-3}$ & $10^{14}$ & $10^{14}$ \\
Beam power, $\mathrm{NW}$ & 85 & 85 \\
Beam energy, keV & 150 & 150 \\
Ave density (burn), $\mathrm{cm}^{-3}$ & $1.3 \times 10^{14}$ & $2 \times 10^{14}$ \\
Ave ion temperature, keV & 18 & 12 \\
Fusion power, MW & 1925 & $1 \mathrm{j} 80$ \\
Beta, : & 3.5 & 3.5 \\
Ripple (plasma edge) : & & 0.34 \\
Start up & 0.84 & 1.60 \\
Burn & 0.84 & \\
\hline
\end{tabular}




\section{LART STEADY-STATE PARAMETERS AS A FUNCTION} OF PLASKIA DENSITY
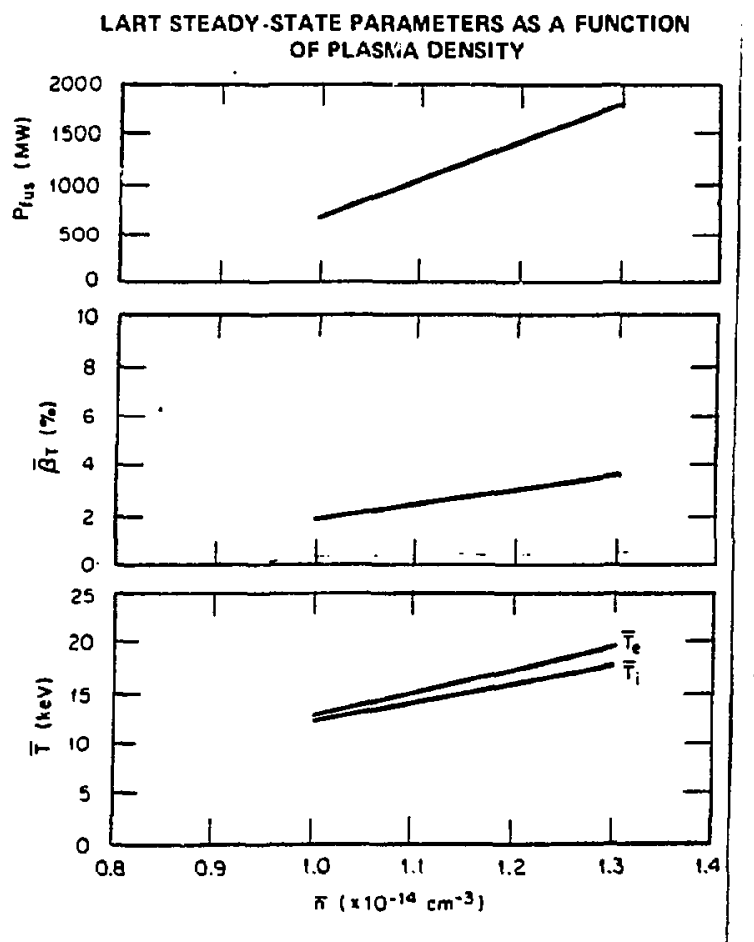

Figure 6

\section{Conclusions}

1. Burn time can be increased an order of magnitude at an increase in unit capital cost of approximately $30 \%$, relative to an ORNL TNS type design, by employing a large aspect ratio design (aspect ratio $=8$, power $=1000$ sive.

2. Alpha containment poses no problem at the lower plasma current, larger aspect ratio points.
3. Accessibility for torus sector removal is not enhanced by large aspect ratios if the convention of butting the inner legs of the TF coils is followed.

4. Ripple at the plasma edge is more stringent for large aspect ratio designs since the magnitude of ripple at the plasma center relative to the value at the plasma edge is greater for large aspect ratio designs.

\section{Reterences}

1. D. Steiner et al., "Oak Ridge TNS Program: Summary of FY 1978 Activities," ORNL/TM-6720, July 1979.

2. A. T. Mense, W. A. Houlberg, S. E. Attenberger, "A 1-D Transport Model for Analysis of Expanding Radius and Full Bore Startup of Tokamak Plasmas," Oak Ridge National Laboratory Report, ORNL/TNJ-6841, (1979)

3. H. Eubank, R. J. Goldston et al., Proc. Plasma Physics and Controlled Nuclear Fusion Research, Vol. I, p. 167 (1978).4, N. A.

4. N. A. Uckan, T. Uckan, J. R. Moore, "Calculation of Magnetic Field Ripple Effects in Circular and Noncircular Tokamaks," Oak Ridge National Laboratory Report, ORNL/TM-5603 (1976)

5. N. A. Uckan, K. T. Tsang, J. D. Callen, "Effects of the Poloidal Variation of the Magnetic Field Ripple on Enhanced Heat Transport in Tokamaks," Oak Ridge National Laboratory Report, ORNL/TM-5438 (1976).

6. J. D. Callen, R. H. Fowler, J. A. Rome, "Alpha Particle Pumping in a Toroidal Fusion Reactor by Magnetic Ripple Effects," Theoretioal Aspects of Controlled Thermonuclear Research (1979) Paper 1 C31. Abstract only. 